\title{
Leitura de book app de literatura infantil na perspectiva dos multiletramentos
}

\section{RESUMO}

Paulo Henrique Machado phenrique14@yahoo.com.br Universidade Tecnológica Federal do Paraná, Curitiba, Paraná, Brasil.

\section{Maria de Lourdes Rossi}

Remenche

mremenche@utfpr.edu.br Universidade Tecnológica Federal do Paraná, Curitiba, Paraná, Brasil.

Eliane Aparecida Galvão Ribeiro Ferreira

eliane@assis.unesp.br

Universidade Estadual Paulista "Júlio

Mesquita Filho", Assis, São Paulo, Brasil.

\begin{abstract}
Este artigo apresenta uma análise das práticas multiletradas de leitura literária em dispositivo móvel de interação, a partir do book app Goldilocks and Little Bear (NOSY CROW, 2015), selecionado para o BolognaRagazzi Digital Award de 2016, na categoria ficção digital. A análise promove a reflexão sobre o efeito das transformações tecnológicas contemporâneas na produção literária infantil, as quais estabelecem novos modos de interação na leitura, suscitando no leitor representações imaginárias que se desenvolvem à medida que a leitura avança. Para tanto, o texto está organizado em duas seções, de forma que a primeira apresenta um breve percurso das perspectivas teórico-conceituais a respeito da leitura literária em meios digitais e das práticas multiletradas mobilizadas. Na segunda, expõe-se o percurso metodológico a partir do aporte teórico da Estética da Recepção (JAUSS, 1994; ISER, 1996, 1999). A análise revela que, apesar da apresentação dos textos escritos e imagéticos em uma mesma página/tela não diferir tanto dos livros ilustrados impressos, tendo os recursos de animação a tarefa de simulação dos efeitos da virada de página, a obra pode ser considerada uma narrativa verdadeiramente interativa, pois se utiliza dos recursos sonoros, cinéticos e de gamificação como potencializadores para a compreensão do enredo narrativo.
\end{abstract}

PALAVRAS-CHAVE: Leitura literária. Multiletramentos. Estética da Recepção. Interação digital. 


\section{INTRODUÇÃO}

$\mathrm{Na}$ contemporaneidade, os livros de literatura infantil têm passado por transformações em seu formato, funcionamento e função, as quais afetam não só os pequenos leitores, como também a cadeia produtiva do livro e, por consequência, toda a sociedade. Os livros impressos, que por tempos se mantiveram como os principais suportes dos textos verbais, visuais e verbovisuais, confrontam-se com formatos digitais $\left(e-b o o k s^{1}\right)$, os quais incorporam multissemioses e possibilitam múltiplas formas de interação entre textos e sujeitos, impactando, sobretudo, nos processos de leitura. Esses livros digitais surgem principalmente como aplicativos para dispositivos móveis de interação ( $e$ readers, smartphones, tablets, entre outros) com telas sensíveis ao toque - daí deriva o nome livro aplicativo ou book $a p p^{2}$, em inglês.

Os book apps são criações híbridas multimodais e multissensoriais (incluem texto escrito, imagem, som, música, movimento, entre outros modos), que potencializam a interatividade, a criatividade e a motivação, e que são acessadas por meio de diferentes dispositivos digitais ${ }^{3}$ (SERAFINI; KACHORSKY; AGUILERA, 2016). Desse modo, oferecem ao leitor/agenciador/usuário mais possibilidades interativas que os livros digitais em formato de arquivo, os quais necessitam de software preexistente para seu funcionamento. De acordo com Leffa e Marzari (2012), um elemento fundamental que diferencia os book apps dos e-books convencionais é a página interativa, que consiste em evento que se instancia em reação a um gesto do participante, capturado por algum dispositivo de entrada (painel, microfone ou câmera), e que resulta em outro gesto, oriundo do objeto, dando algum tipo de resposta.

Assim sendo, a partir da incorporação de recursos multimídia e de interação em suporte eletrônico, verificam-se alterações não apenas nas configurações de leitura destas obras, como também em seu processo de produção gráfica, uma vez que o design da estrutura narrativa deixou de ser pensado a partir da página dupla impressa para se comportar como interface, fato que leva a acreditar que a estruturação dos elementos verbo-viso-sonoros no livro digital possa diferir da forma que é apresentada e projetada nos livros ilustrados impressos. Cabe salientar ainda que, cada vez mais cedo, as crianças começam a ter acesso e a utilizar dispositivos eletrônicos portáteis repletos de recursos interativos, fato que, de acordo com Turrión (2014), tem impulsionado o crescimento do mercado de aplicativos infantis de todos os tipos: educativos, jogos, leitura informacional e, por sua vez, leitura literária.

Embora a maioria dos book apps existentes sejam remidiações de publicações impressas, isto é, quando as mesmas obras circulam em ambos os suportes (CORRERO; REAL, 2014), verifica-se o crescimento do número de obras criadas exclusivamente para o meio digital. Frente à nova indústria editorial dos livros literários infantis digitais, verifica-se a tentativa de inclusão desses artefatos em premiações concedidas por entidades de referência em trabalhos voltados para a discussão e o incentivo da leitura para crianças e jovens. No cenário internacional, a Feira do Livro Infantil de Bolonha (Itália), considerada a mais importante mundialmente, a partir de 2012, passou a premiar com o BolognaRagazzi Digital Award ${ }^{4}$ as propostas digitais mais inovadoras, entre aplicativos derivados de livros. No Brasil, no ano de 2015, o Prêmio Jabutit ${ }^{5}$ inovou em sua 57ạ edição com a inclusão da categoria "Infantil Digital"6, que contemplava a participação de 
produções infantis digitais interativas compostas por diferentes combinações de linguagens, articuladas com algumas possibilidades de interação.

Nesse panorama, este estudo objetiva apresentar uma investigação a respeito das práticas multiletradas de leitura literária em dispositivo móvel de interação, a partir de uma análise do book app Goldilocks and Little Bear (NOSY CROW, 2015), selecionado para o BolognaRagazzi Digital Award de 2016, na categoria ficção digital. Na análise desse book app, visa-se refletir sobre o efeito das transformações tecnológicas contemporâneas na produção literária infantil, as quais estabelecem novos modos de interação na leitura, suscitando na consciência do leitor representações imaginárias (ISER, 1996), as quais se desenvolvem à medida que a leitura avança.

Com vistas à consecução do objetivo, este artigo estrutura-se em duas seções. A primeira apresenta um breve percurso das perspectivas teórico-conceituais a respeito da leitura literária em meios digitais e os multiletramentos que essa atividade requer. A segunda expõe o percurso metodológico de análise da obra eleita como objeto de estudo, a partir, também, do aporte teórico da Estética da Recepção (JAUSS, 1994; ISER, 1996, 1999). No ato de ler, conforme Jauss, pode-se observar que "a qualidade e a categoria de uma obra literária não resultam nem das condições históricas ou biográficas de seu nascimento [...], mas dos critérios da recepção, do efeito produzido e de sua fama junto à posteridade" (1994, p. 7).

Diante da oferta de produtos e mídias passíveis de leitura, acentua-se a preocupação com a formação do leitor e a importância do receptor na concretização do texto literário. Busca-se compreender, então, a partir dos estudos sobre a teoria do efeito estético desenvolvidos por Iser (1996), se o book app Goldilocks and Little Bear (NOSY CROW, 2015) atualiza os elementos potenciais do texto, pela promoção de emoções no leitor. Para Iser, retomando Roman Ingarden, é a emoção que "provoca aquela turbulência no leitor que dá partida à atividade constitutiva e só se tranquiliza quando produz o objeto estético" (1999, p. 113). As considerações finais apresentam a síntese da investigação descrita neste estudo.

\section{LEITURA EM MEIOS DIGITAIS E MULTILETRAMENTOS}

A leitura é uma atividade plural, complexa, que se desenvolve em várias direções e que pode ser estudada e compreendida por meio de diversos enfoques. Jouve (2002) compreende-a como uma atividade multifacetada e multidimensional, diretamente relacionada com cinco processos: neurofisiológico, cognitivo, afetivo, argumentativo e simbólico. Para o estudioso, trata-se de um ato concreto, observável, que suscita visão e diferentes funções cerebrais, consistindo em "uma operação de percepção, de identificação e de memorização dos signos." (JOUVE, 2002, p. 17). Conforme Kleiman (2011), justamente porque o leitor utiliza diversos níveis de conhecimento que interagem entre si - tais como, o linguístico, o textual e o de mundo -, a leitura é considerada um processo interativo. Essencialmente, ela consiste no compartilhamento dos sentidos de uma sociedade, e o ato de ler é um processo que, "qualquer que seja o seu ponto de partida teórico, passa necessariamente pelo leitor, autor, texto e contexto. Sem um deles, o circuito não se completa e o processo resulta falho." (COSSON, 2014, p. 41). 
O processo de formação de leitores está interligado à literatura infantil, cuja importância no desenvolvimento psicossocial da criança e no processo de aprendizagem tem incitado estudos concernentes à sua função de aprimorar no leitor o gosto e a prática da leitura em diferentes linguagens e suportes (MACHADO; REMENCHE, 2017). Lajolo e Zilberman (2017) evidenciam que a literatura endereçada às crianças consiste em valiosa contribuição à história bibliográfica e literária, sendo essencial para as práticas letradas e para a cultura, além de estar na vanguarda das experiências que utilizam técnicas multi/hipermidiáticas, em que imperam as relações verbo-viso-sonoras em narrativas, em lugar da palavra escrita, simplesmente. Ferreira (2009, p. 114) argumenta que a literatura infantil contemporânea "procura, por meio da autocrítica [...], da metalinguagem, da dialogia, da intertextualidade, adequar-se às peculiaridades próprias do tipo de leitor a quem se destina." Para a estudiosa, o efeito de uma obra é produzido "quando existem leitores que novamente se apropriam da obra passada ou autores que desejam imitá-la, sobrepujá-la ou refutá-la, enfim, quando ocorre dialogia." (FERREIRA, 2009, p. 225).

As transformações tecnológicas das últimas décadas, proporcionadas pela globalização e pela popularização dos computadores pessoais e dos dispositivos móveis de interação, têm impactado as formas de ler, de escrever, de se expressar, e de ver e entender o mundo. As práticas sociais linguageiras geraram uma crescente demanda por letramentos que considerem os diversos modos de enunciação (linguístico, visual, sonoro, gestual, espacial) e a capacidade de misturá-los ou interligá-los. Assim sendo, os textos contemporâneos deixam de ter o predomínio da fala ou da escrita (modalidade verbal) para expressar o sentido em uma combinação de vários modos de representação por imagens estáticas e em movimento (fotos, ilustrações, grafismos, vídeos, animações - modalidade visual), áudio (música e outros sons não verbais - modalidade sonora), linguagem corporal (gestualidade, danças, performances, vestimentas - modalidade gestual), e o espaço da página e das telas digitais (KRESS; VAN LEEUWEN, 1996; ROJO; BARBOSA, 2015). Consequentemente, a formação de leitores capazes de se apropriarem dos textos multimodais produzidos e disponibilizados digitalmente demanda múltiplos letramentos, os quais deverão abarcar variadas práticas e usos que envolvem tal fenômeno.

Desse modo, não basta ao sujeito ser letrado para ler e escrever, é preciso desenvolver múltiplos letramentos para os textos que incorporam uma nova identidade pelas múltiplas representações de significado em sua composição na página impressa ou na tela digital para a compreensão oral e escrita (COPE; KALANTZIS, 2009). Tais procedimentos exigem o desenvolvimento de diferentes habilidades, fazendo emergir os estudos relacionados aos múltiplos (e novos) letramentos - informacional (busca e uso críticos da informação), visual (uso das imagens), digital (uso das tecnologias digitais), entre outros - ou os multiletramentos.

Yokota e Teale (2014) consideram que as habilidades para o processamento e a produção de textos multi/hipermidiáticos são essenciais para que um sujeito seja considerado multiletrado no século XXI, e as interações com livros digitais na primeira infância podem se constituir profícuas para o início da construção dessas habilidades, uma vez que "a compreensão de grande parte dos efeitos literários e dos sentidos produzidos em obras digitais requer a compreensão de códigos e 
textualidades específicas do universo digital" (KIRCHOF, 2016, p. 223), demandando, para a leitura, uma atividade mais lúdica e exploratória do leitor.

Essa produção literária específica da virtualidade, denominada literatura digital ou eletrônica, "é movida pelos motores da cultura contemporânea, especialmente jogos de computador, filmes, animações, artes digitais, desenho gráfico e cultura visual eletrônica." (HAYLES, 2009, p. 21). Com o surgimento do iPad em 2010, diversas obras foram produzidas diretamente em meio digital, constituindo-se em "novo formato de expressão literária voltado ao público infantil que expande as narrativas verbovisuais características do livro ilustrado impresso ao incorporar sons, movimentos e interatividade." (FREDERICO, 2016, p. 105).

Novais (2012) afirma que a leitura da interface gráfica - tecnologia de representação que permite a mediação das ações no ambiente digital, integrando de forma coerente e sensível os processos digitais - vai exigir do leitor habilidades de navegação muito bem desenvolvidas e a construção de associações e inferências eficazes. A construção de sentido na interface gráfica "não está relacionada apenas à decodificação de seus elementos estruturantes, mas sim ao reconhecimento de uma complexa rede de relações entre esses elementos." (NOVAIS, 2012, p. 15).

Assim, com o surgimento de práticas específicas inerentes ao meio digital, os sujeitos são impelidos a complexificar a representação que fazem da comunicação verbal. Em função dessa integração multi/hipermodal, a leitura passou a ser "navegante" (RIBEIRO, 2011; COSCARELLI, 2016), uma vez que cada leitor pode fabricar seu próprio texto/hipertexto a partir das escolhas e dos caminhos que opta durante sua navegação. Coscarelli (2016) afirma que a leitura na Internet e em ambientes digitais, denominada "leitura online", envolve habilidades diferentes, que incluem a navegação, competência complexa que é "provavelmente responsável por grande parte das diferenças que encontramos na pesquisa de leitura 'tradicional' (do impresso) em comparação com a leitura online." (COSCARELLI, 2016, p. 68, grifo da autora).

Ribeiro (2011), ao tratar sobre a leitura na tela, ressalta que os leitores infantis se adaptam aos novos suportes, aos novos objetos de ler, e os novos objetos vão sendo refinados e projetados de acordo com as demandas dos leitores, fundamentadas no uso. Cada nova interface guarda características de suas predecessoras, e "tudo isso faz com que o leitor não precise, a rigor, começar do zero ao lidar com um novo recurso, uma nova tecnologia de objeto de ler." (RIBEIRO, 2011, p. 130).

Em virtude das particularidades do meio digital, são possibilitadas novas formas de organização dos conteúdos nos book apps. Enquanto nos livros impressos o texto verbal e as imagens se relacionam no espaço pouco mutável da página dupla (o conjunto formado pelas páginas par e ímpar justapostas, unidas pela dobra do livro), a superfície de organização nos livros aplicativos possibilita a superposição de elementos em camadas e a expansão das dimensões do espaço representativo em todas as direções a partir de ações como deslizar a imagem pela área visível da tela. Como cada book app pode conter organizações muito diferentes de composição estrutural em função da gama de potencialidades dos suportes tecnológicos, cabe considerar que, mesmo em ambiente digital, eles 
estão condicionados a uma área delimitada de exploração, isto é, a dimensão da tela do dispositivo móvel (PEREIRA, 2017).

Destacam-se as principais funções que os elementos interativos executam dentro dos book apps (STICHNOTHE, 2014; MENEGAZZI, 2018): criar tensão entre texto verbal e imagem, texto verbal e som, imagem e som; impulsionar o desenvolvimento da narrativa; adicionar humor; fornecer informações extras; sugerir atividades para o leitor dentro do aplicativo ou no mundo real; oferecer a oportunidade de gravar a própria voz, lendo a história ou criando uma nova; oferecer a possibilidade de escolher entre diferentes elementos narrativos, acionar áreas, desencadear ações ou dar acesso a conteúdos extras.

Nos book apps, a interatividade exige a agentividade do leitor para fazer ligações entre objetos distintos, possibilitando movimentação deliberada por meio do conteúdo de forma não linear, diferente do livro impresso, que é essencialmente linear, em que o leitor não pode interferir na narrativa literária. Gosciola (2008) explica que os conteúdos apresentados em meios híbridos devem preservar a unidade em seu conteúdo para que o leitor a perceba como uma única obra, uma vez que cada elemento inserido na tela poderá romper a linearidade da expressão narrativa. Nesse sentido, Teixeira e Gonçalves (2016) advertem para a importância de se conhecer o design de narrativa digital para organizar as diferentes mídias e interatividades em book apps com o intuito de transmitir histórias de maneira efetiva. Conforme Menegazzi e Debus, "as contribuições dos conhecimentos e práticas de design podem favorecer inúmeras instâncias no que se trata da materialização dos livros infantis." (2018, p. 283).

Entre os recursos de interatividade observados em book apps, destacam-se os desafios inseridos na experiência da narrativa. Tal característica faz com que a leitura nesses artefatos possa ser englobada na esfera de experiências que sofrem gamificação. Kapp (2012) afirma que a gamificação consiste na utilização de elementos dos jogos digitais (mecânicas, estratégias, pensamentos) fora do seu contexto original, com a finalidade de motivar os sujeitos à ação, auxiliar na solução de problemas e promover aprendizagens. É uma aplicação cuidadosa do pensamento dos games para encorajar a aprendizagem, utilizando todos os elementos "jogáveis" que forem apropriados. Rogers, Sharp e Preece (2013) evidenciam ainda a relevância em considerar como o leitor/usuário se sentirá ao interagir com o artefato (o dispositivo em que roda o book app).

Torna-se extremamente relevante, então, refletir a respeito das transformações que as tecnologias digitais provocam no conceito de livro e como essas mudanças propiciam novas formas, tempos e espaços de leitura, considerando o uso cada vez mais precoce das tecnologias digitais por parte das crianças, aliada à incipiente produção de livros literários infantis em meio digital.

\section{ANÁLISE DE GOLDILOCKS AND LITTLE BEAR}

No âmbito da Linguística Aplicada, as pesquisas que focalizam os Multiletramentos (COPE; KALANTZIS, 2009) com vistas à formação do leitor crítico (ECO, 2003), por sua preocupação com os usos reais de linguagens, em especial, a literária, têm adotado metodologias de caráter qualitativo, por meio da aplicação de procedimentos interpretativos na negociação do significado na sociedade (MOITA LOPES, 1996). 
O foco de uma pedagogia para os multiletramentos recai não somente no modo linguístico, mas em outros modos de significação para complementá-lo visual, sonoro, gestual e espacial -, tendo em vista a comunicação por meio de textos multissemióticos forjados pelas potencialidades das tecnologias (COPE; KALANTZIS, 2009). Nesse sentido, os multiletramentos apontam para dois tipos de "múltiplos" que as práticas de letramento contemporâneas envolvem: por um lado, a multiplicidade de linguagens, semioses e mídias envolvidas na criação de significação para os textos multimodais e, por outro, a pluralidade e diversidade cultural trazida pelos autores/leitores contemporâneos a essa criação de significação (ROJO, 2013).

Delimitou-se, como corpus de pesquisa, a obra literária Goldilocks and Little Bear (NOSY CROW, 2015), que se caracteriza, segundo Yokota e Teale (2014), em transformação de livro de literatura infantil para inclusão de recursos digitais. Utilizou-se como principal critério de seleção a pertinência da obra ao gênero narrativo, uma vez que considerável quantidade de book apps disponíveis se enquadra em outros gêneros literários (como o lírico) ou não podem ser caracterizados como literários (constituem-se em leitura de informação, com finalidade prática e utilitária). Apresenta-se, na sequência, uma amostra da ocorrência das interfaces e interações multimodais em Goldilocks and Little Bearassociada aos elementos narrativos e estruturais - que mobilizam práticas multiletradas de leitura.

Goldilocks and Little Bear é um book app desenvolvido em 2015 para dispositivos iOS (Apple) pela equipe de escritores, ilustradores e designers da Nosy Crow, uma premiada editora infantil independente, sediada em Londres. Com a presença de ambientes virtuais imersivos e animações (ativadas por meio do toque na tela ou automáticas), o book app também utiliza recursos de câmera, giroscópio (visão 360ㅇ) e acelerômetro ${ }^{7}$. Quando concorreu ao BolognaRagazzi Digital Award de 2016, os jurados relataram que a experiência de leitura/agenciamento nesse book app é um deleite do começo ao fim, por conter recursos táteis bem projetados, música especializada, gráficos feitos para o meio interativo e uma narração infantil de última geração. Trata-se de um reconto ${ }^{8}$ do clássico conto de fadas A História dos Três Ursos, popularmente conhecido pelo nome de sua protagonista, Cachinhos Dourados. A história foi recontada com inteligência e humor em duas narrativas paralelas, aproveitando as potencialidades dos recursos tecnológicos digitais.

Enquanto a garota está na casa dos ursos, comendo mingau, sentando em suas cadeiras e dormindo em suas camas, o pequeno urso está na casa da família de Goldilocks, comendo suas panquecas, vestindo roupas e lendo seus livros. Ao final, todas as personagens - incluindo aí o pai e a mãe da menina -, se encontram e se tornam amigos, proporcionando um reconto contemporâneo da história clássica.

A sequência narrativa da história da personagem Goldilocks segue basicamente o enredo do conto clássico, contudo, com três inclusões que alteram drasticamente as questões analíticas da trama: a menina tem uma casa na floresta, há a presença de seu pai e de sua mãe, e toda a família explora a floresta em que vive. O mote para que as narrativas pararelas se desenvolvam é a equivalência de elementos e personagens: as duas casas, as duas famílias e a mesma floresta. Todavia, enquanto os autores procuram respeitar a narrativa da personagem Goldilocks o mais fielmente possível ao conto original, ousam nos elementos "cênicos" da narrativa de Little Bear. Ao entrar na casa de Goldilocks, o ursinho 
experimenta as panquecas, usa as roupas e acessórios dos armários, lê os livros nas poltronas e adormece na última.

Na sequência, os pais de Goldilocks, acreditando que a menina possa ter retornado a casa, se assustam quando verificam a desorganização realizada por Little Bear, que, quando acorda e vê os humanos, sai em disparada pela floresta, sendo perseguido por eles. Quando menos espera, Little Bear colide com Goldilocks, que fugia da perseguição dos ursos. O encontro dos protagonistas e de seus familiares caracteriza o ponto de convergência das duas narrativas, que possuem o mesmo desfecho na realização de um piquenique no meio da floresta, com direito a novos passeios e à brincadeira de esconde-esconde (Figura 1).

Figura 1 - Pontos de convergência das narrativas em Goldilocks and Little Bear

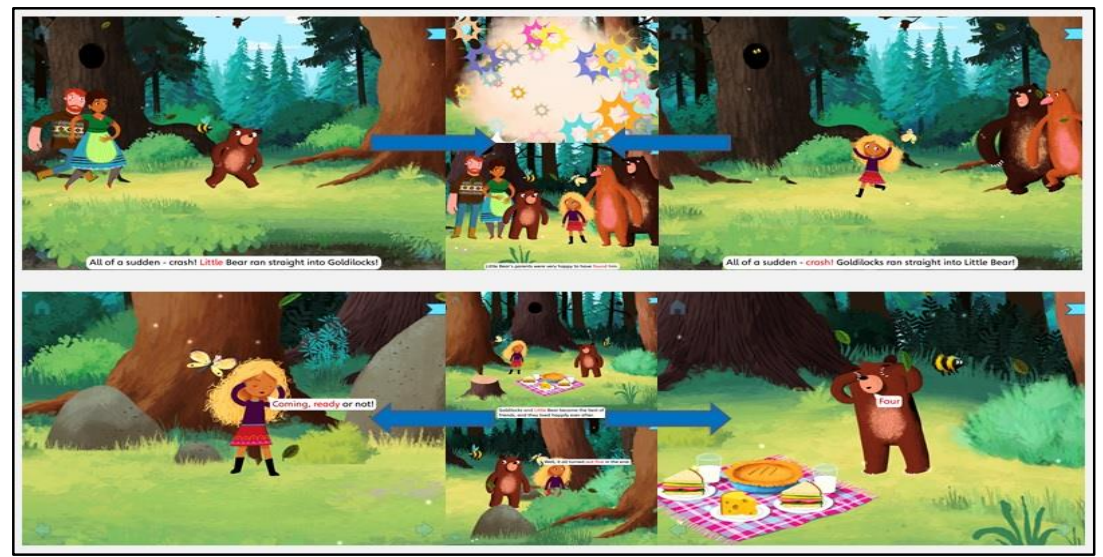

Fonte: NOSY CROW (2015).

Mesmo com o recurso interativo que permite a transição abrupta entre as narrativas paralelas, verificou-se que há manutenção da integridade da narrativa. Caso o leitor se perca durante as mudanças, no canto superior direito, por meio de uma aba na cor azul, é disponibilizado um mapa que retrata as duas narrativas - a de Goldilocks na parte superior e a de Little Bear na inferior - desde o ponto em que se iniciam nas casas dos protagonistas, até o ponto de convergência, representado pelo encontro das duas famílias e a realização de um piquenique na floresta.

Constatou-se que esse reconto (NOSY CROW, 2015), pela revitalização do conto de fadas Cachinhos Dourados, proveniente da oralidade, permite ao leitor ativar sua memória transtextual (FERREIRA, 2009) durante a leitura do texto literário, revelando o caráter dialógico da narrativa. As versões mais antigas desse conto foram escritas por Eleanor Mure em 1831, para seu sobrinho de seis anos e, em 1937, por Robert Southey com o título Cachinhos de Ouro e os Três Ursos; em ambas, a invasora da casa dos ursos era uma velha. A protagonista assume a identidade de uma menininha em uma versão de 1850 (CORSO; CORSO, 2006).

Assim como no original, no reconto da Nosy Crow (2015), não há uma lição de moral explícita. Simplesmente, transmite-se a mensagem de que não é conveniente invadir propriedades alheias e usufruir dos utensílios sem a devida permissão. No entanto, diferentemente do conto matricial, em que a floresta não possui relevância para a trama, no reconto em aplicativo, ela é de suma importância enquanto elo das histórias de Little Bear e de Goldilocks. A floresta configura-se como cenário para vários acontecimentos, nela desenvolvem-se parte 
significativa do clímax e o desfecho. Nesse espaço, a temporalidade é marcada pelas performances das personagens associadas às suas emoções.

Em book apps como este, que utiliza imagens como mídia preponderante, as ilustrações sofrem influência dos livros literários infantis impressos e das histórias em quadrinhos, podendo se apresentar, segundo Linden (2011), de forma isolada, sequencial ou associada. As ilustrações de Goldilocks and Little Bear são artísticas, possuem pregnância estética e dialogam com o texto escrito, ampliando os significados das narrativas. Em diversos momentos, ilustrações e texto verbal escrito/falado estabelecem relações de colaboração e de redundância (LINDEN, 2011), principalmente nesta última, em virtude de a obra seguir os moldes do conto de fadas original, em que as repetições frasais são peculiares. No tocante ao texto verbal escrito, verificou-se que, com exceção da capa (tela inicial), em que se misturam fontes e famílias tipográficas na composição do título e dos menus de acesso, há padronização em sua exibição, tanto nas falas das personagens quanto nas falas do narrador, que se apresentam em caixas de textos, que lembram os balões das histórias em quadrinhos. As letras possuem boa leiturabilidade e legibilidade, apresentadas em caixas alta e baixa, em coloração preta e vermelha sobre fundo branco.

Os recursos de transição (SERAFINI; KACHORSKY; AGUILERA, 2016) dizem respeito aos modos como o leitor/agenciador transita de uma tela para a outra do livro digital interativo. Goldilocks and Little Bear possui três recursos de transição de tela (Figura 2): efeito zoom in/out (transição suave de puxada para dentro e para fora da tela), toque em setas (esquerda/voltar e direita/avançar) e giro do aparelho na posição vertical. Este book app também possui um recurso muito interessante de movimentação das personagens, em que o leitor/agenciador, por meio de toque e pressionamento na tela, consegue fazê-las andar ou correr por toda a extensão dos cenários disponíveis, no interior das casas e pela floresta. As falas das personagens são simultaneamente transmitidas ao leitor por meio de balões, que superpõem quaisquer outros elementos dos cenários. Além dos balões de fala, ícones e abas constituem elementos que têm prioridade de superposição. A seguir, podem-se visualizar esses recursos.

Figura 2 - Recursos de transição de tela em Goldilocks and Little Bear

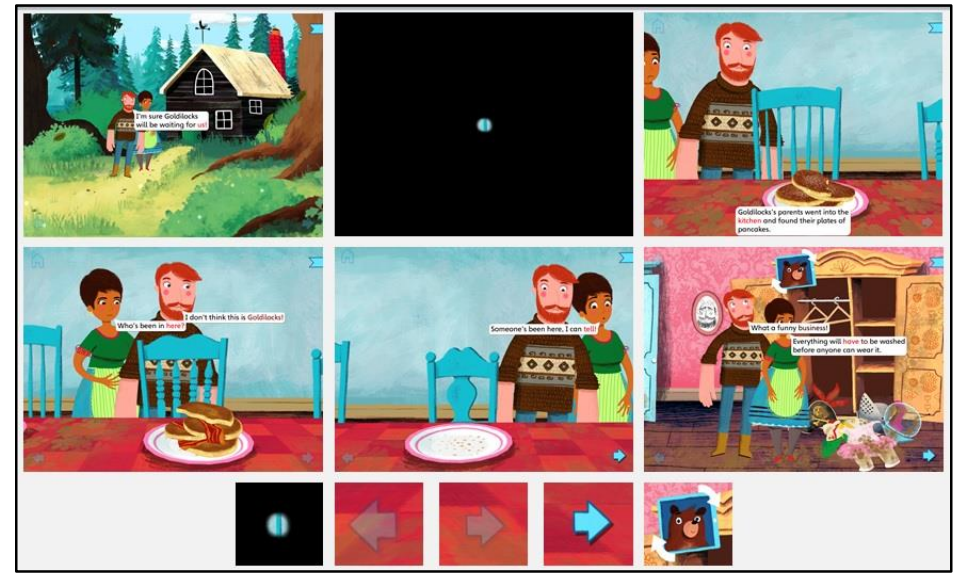

Fonte: NOSY CROW (2015).

A obra contempla ainda recursos de interação por movimento do dispositivo móvel. Em determinados momentos das narrativas, é possível ao leitor/agenciador 
"saltar" de uma história para a outra, por meio da mudança da posição do dispositivo (giro de 180으, na vertical, simulando o movimento de um volante de carro) para acompanhar, paralelamente, as aventuras dos dois protagonistas (a menina e o pequeno urso). Na cena em que Goldilocks senta-se na cadeira de Little Bear para experimentá-la, o leitor/agenciador pode realizar movimentos pendulares no aparelho para acionar o balanço (Figura 3). Quanto mais rápido o aparelho é movimentado, mais intenso será o balanço da cadeira, que, inevitavelmente, se despedaça, conforme exposto a seguir.

Figura 3 - Movimentação do iPad na história de Goldilocks

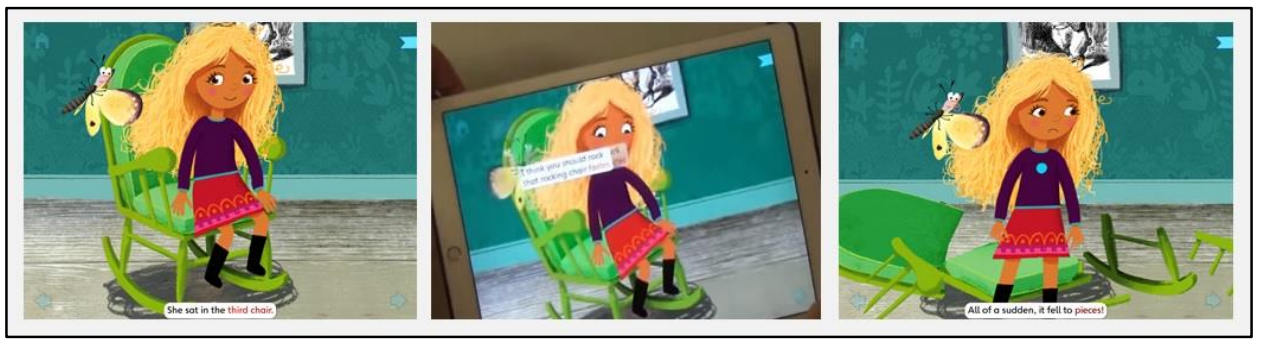

Fonte: NOSY CROW (2015).

As animações existentes em Goldilocks and Little Bear são bem estruturadas em relação à narratividade das duas histórias presentes no book app. Em grande parte da obra, os recursos automáticos de animação aceitam e/ou requerem a intervenção do leitor/agenciador para a realização de ações efêmeras. A Figura 4, por exemplo, mostra a cena em que Little Bear acaba de fugir da casa de Goldilocks e é perseguido pelos pais da menina, floresta adentro. Enquanto corre, o ursinho solicita ajuda para pular os pedaços de troncos de árvores que bloqueiam o caminho. Vale destacar que a interatividade com o leitor é suscitada pelo discurso do próprio protagonista. Cabe ao leitor tocar sobre eles, simulando com o dedo indicador o movimento de pulo. Caso o leitor não o faça, o ursinho tropeça em todos os troncos existentes até o momento em que colide com seus pais e Goldilocks, reclamando e se perguntando quem poderia tê-los colocado ali, pois não os havia visto na ida.

Figura 4 - Animação em Goldilocks and Little Bear

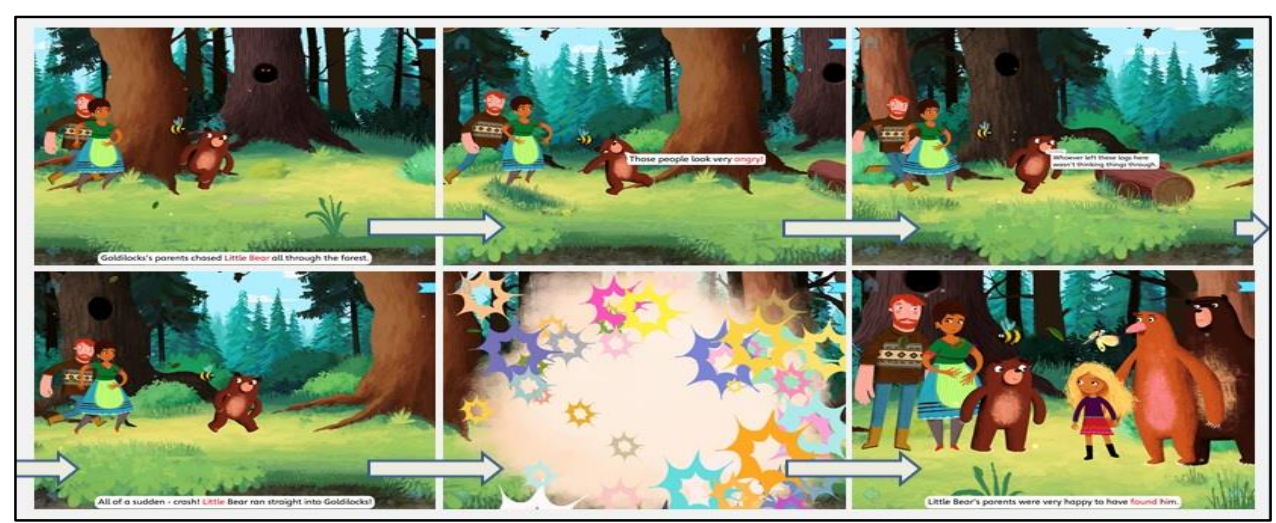

Fonte: NOSY CROW (2015).

Na obra, as estruturas de áudio são utilizadas como elementos midiáticos que auxiliam no direcionamento das histórias contadas, com o objetivo de produzir 
experiências sonoras em seus ouvintes, indicar caminhos, objetos e eventos. Ela apresenta trilha sonora composta pelas vozes de todas as personagens e do narrador, efeitos sonoros nos elementos cênicos e nos recursos de transição, ruídos mnemônicos e onomatopaicos, e músicas diegéticas e não-diegéticas. A Figura 5 mostra alguns exemplos: a família de Goldilocks dialogando durante o café da manhã; o ranger da cama enquanto a menina pula agenciada pelo leitor; o som do ressonar de Goldilocks enquanto dorme profundamente na cama de Little Bear, acompanhado graficamente por uma sequência de "Zês" (Zzz... - palavra onomatopaica que designa ruído contínuo, como os produzidos pela respiração de quem dorme); o passeio de Goldilocks é ambientado com música de fundo e ruídos característicos da floresta. Como se pode notar, recursos estilísticos avultam no plano sonoro, verbal e imagético, suscitando interação com o jovem leitor. Por isso, podem desautomatizar seus conceitos prévios de associação da leitura à atitude passiva de expectador.

Figura 5 - Presença de trilha sonora em Goldilocks and Little Bear

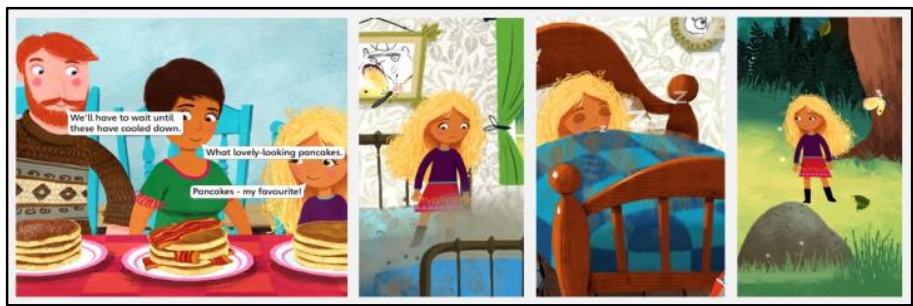

Fonte: NOSY CROW (2015)

Goldilocks and Little Bear é repleto de elementos de gamificação, que se apresentam ao longo das narrativas a partir dos recursos interativos de agenciamento disponíveis ao leitor. Na Figura 6, por exemplo, são mostrados dois momentos em que o leitor pode brincar com as personagens: no primeiro, faz-se Goldilocks pular nas camas dos três ursos, por meio da movimentação (para cima e para baixo) do dedo indicador; no segundo, veste-se Little Bear com as roupas e os acessórios presentes nos três guarda-roupas do quarto dos humanos. Instala-se - lúdico na interatividade, convocando o pequeno leitor ao jogo da experimentação pelo viés do cômico.

Figura 6 - Elementos de gamificação em Goldilocks and Little Bear

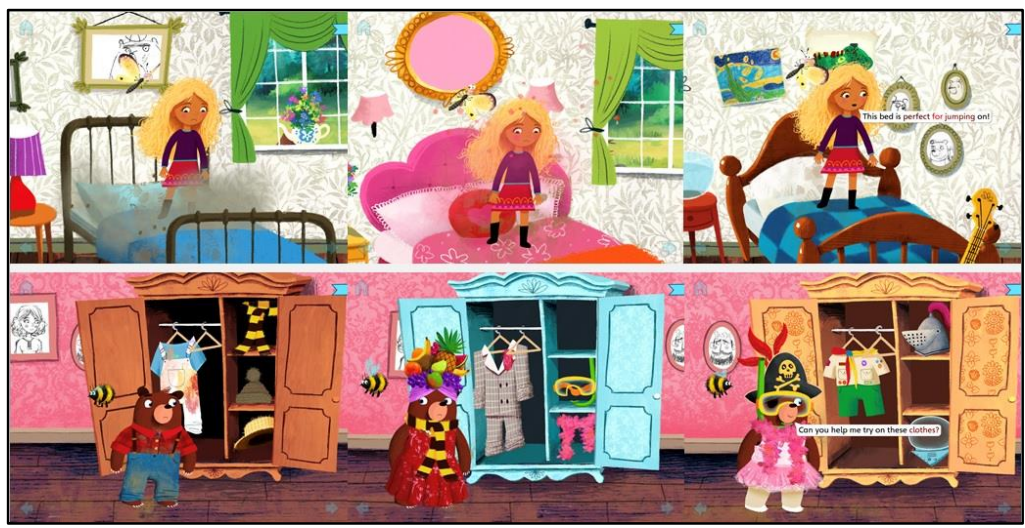

Fonte: NOSY CROW (2015). 
Verifica-se que a característica marcante desse book app é a presença corporal do leitor/agenciador em relação ao dispositivo, pois o sujeito precisa, em cada cenário adentrado, executar movimentos para acompanhar a trajetória das personagens. Nesse sentido, a obra exige do leitor o empenho do seu corpo (intensidade de presença), variações recriadoras e movência, em que a leitura pode ser caracterizada como performática. De acordo com Zumthor (2018), reside na "performance" toda uma sintonia entre palavra, imagem, som, corpo e gestualidade, que dá ênfase ao que está sendo contado/narrado/experienciado, isto é, a vivificação das textualidades. Vale destacar que a performance, por sua vez, promove a emoção que assegura a permanência do interesse pela leitura.

Esse interesse também é mantido pela possibilidade de diferentes rumos para a história, o que produz vazios, lacunas suplementares - preenchidas durante a leitura pelas projeções do leitor - as quais capturam o leitor em formação pela curiosidade e pelo desalojar de suas expectativas (ISER, 1979, 1996, 1999).

Nota-se, ainda, que como obra pós-moderna, a narrativa de Goldilocks and Little Bear recorre a assuntos pertinentes à realidade social contemporânea, por meio da "apropriação irônica, debochada mesmo, de ícones do consumo [...]" (RESENDE, 2008, p. 20). Essa crítica se intensifica nas cenas em que o protagonista urso experimenta inúmeras roupas e acessórios, retirados dos guarda-roupas da mãe, do pai e de Goldilocks. O humor avulta na permanência do elemento cômico, pela junção de peças díspares entre si, bem como de acessórios que remetem à fantasia, ao jogo, ao imaginário.

Percebe-se no book app que sua composição oportuniza abordagens pertinentes para a formação crítica das crianças que, consequentemente, favorecem seus processos cognitivos, tornando-as mais ativas e autônomas. Pela resolução do conflito entre as famílias e pela ausência de castigos para os protagonistas mirins que se afastam de seus pais e promovem desorganização nos espaços que adentram, pode-se observar uma crítica a atitudes pautadas pela violência que desrespeitam o anseio das crianças de realizar descobertas pela experimentação. A promoção do encontro entre os pequenos protagonistas reforça a percepção de que crianças precisam de convívio e interação, por meio de brincadeiras e descontração. Pode-se perceber que toda essa reflexão acerca da aquisição de um saber para os protagonistas é proveniente da interação.

Assim, como espelho, o livro indica, ao seu leitor implícito (JAUSS, 1994; ISER, 1996, 1999), que a sua aquisição de conhecimentos também se efetiva na interação, por meio do toque na tela, e pela brincadeira - jogo instalado durante a leitura - de escolher o rumo da história e interferir no comportamento das personagens. Enfim, na obra, os diversos modos de enunciação atuam como potencializadores da interatividade na leitura, da compreensão do enredo narrativo e do instalar de vazios, que asseguram a manutenção do suspense e do desejo de saber do leitor.

A quebra de expectativa que a obra propicia ao jovem leitor é resultante da revisão de conceitos prévios que ele possui e da revisão de hipóteses formuladas durante o processo de interpretação. Essa quebra de expectativa, seguida de situações inesperadas, é resultado da interrupção da conectabilidade observada, que produz o vazio. O vazio sinaliza tanto a ausência de conexão quanto as expectativas do uso habitual da linguagem, no qual a conectabilidade é pragmaticamente regulada. O texto ficcional, ao propiciar retomada de 
pressupostos ao leitor, adquire sua função, não pela comparação com a realidade, mas sim pela mediação de uma realidade que se organiza por ela. Dessa forma, a ficção transcende o mundo a que se refere (ISER, 1979; FERREIRA, 2009).

\section{CONSIDERAÇÕES FINAIS}

Em Goldilocks and Little Bear, constatou-se que a apresentação dos textos escritos e imagéticos em uma mesma página/tela não difere tanto dos livros ilustrados impressos, assim como, na maneira como essas linguagens se interrelacionam. Ademais, percebeu-se que a lógica de concepção do livro impresso a partir dos efeitos produzidos pelos registros verbovisuais em página dupla foi transposta diretamente para a tela digital, normalmente aparecendo em apenas uma página/tela, cabendo aos recursos de animação a tarefa de simulação dos efeitos característicos da tradicional virada de página, por intermédio do agenciamento.

Como se pode notar, seus recursos de interação conferem, durante a leitura, ludicidade e possibilidade de imersão ao jovem leitor. Além disso, seus elementos literários e artísticos são suficientes para cativar esse leitor em formação e instigálo à navegação pelo viés da exploração não só de recursos, mas também de rumos ao desenrolar da narrativa. Embora a obra possa ser lida pela criança sem ajuda de um mediador, a sua exploração em âmbito escolar pode fomentar, para o pequeno leitor, a percepção e a valoração dos aspectos literários e artísticos da obra.

Nesse book app, quando os textos verbovisuais atingem os limites da área da tela, agem como ocorre na página dupla do impresso, todavia, configuram-se como janelas que projetam os leitores/agenciadores para dentro (e para fora) da narrativa por meio de processos imersivos. Isso ocorre em virtude de as textualidades existirem em consonância com o suporte do aplicativo, as quais passam a se reorganizar de acordo com as funções projetadas para esse novo artefato de leitura. Consequentemente, os leitores são convidados a reconfigurar suas relações com o book app, disponibilizando-se a interatuar com interfaces multimodais.

Goldilocks and Little Bear pode ser considerada uma narrativa verdadeiramente interativa, pois se utiliza dos recursos sonoros, cinéticos e de gamificação como potencializadores para a compreensão do enredo narrativo, e não como meros recursos adicionais. Observou-se que, na medida em que os sujeitos leem/agenciam, também são interpelados sobre questões relativas à sua corporeidade.

Dessa forma, a(s) leitura(s) possibilitadas nas/pelas páginas/telas multitouch do book app em questão mobilizam múltiplas habilidades dos sujeitos, visto que novas estratégias são demandadas para a produção de sentidos, considerando a articulação de diferentes linguagens. A combinação multimodal nesse book app, aliada à agentividade dos leitores e às potencialidades das tecnologias digitais, aciona modos diferenciados de leitura e demanda maior interatividade por parte do leitor.

A realização desta pesquisa possibilitou a percepção das configurações no design das linguagens e das modalidades textuais em book apps, assim como, das práticas multiletradas acionadas na formação de leitores na infância. O livro digital interativo em formato de aplicativo escolhido para compor o corpus de pesquisa 
possibilita ao leitor/agenciador interagir ludicamente entre diversos recursos que mesclam o texto literário com elementos multissemióticos. A persuasão ao público infantil ocorre por meio da inter-relação entre leitura, agenciamento, composição e os recursos que se assemelham aos utilizados pelos jogos eletrônicos.

Entende-se que os book apps estão dando seus primeiros passos no mercado editorial e, em virtude da exponencial velocidade do desenvolvimento tecnológico, torna-se difícil a mensuração dos futuros avanços, ou quem sabe, de sua obsolescência ou repentino declínio, face à emergência de novas tecnologias. Almeja-se que os book apps infantis produzidos na contemporaneidade, principalmente os brasileiros, integrem funcionalidades próprias do ambiente digital que permitam a adaptação dos conteúdos frente à experiência de leitura e às preferências dos leitores, sejam elas relacionadas com a integração desses conteúdos nos aplicativos e/ou com a estruturação das interfaces usadas no design das páginas interativas. 


\title{
Children's literature book app reading from the perspective of multiliteracies
}

\begin{abstract}
This article presents an analysis of the multiliteracy practices of literary reading on a mobileinteraction device, based on the Goldilocks and Little Bear (NOSY CROW, 2015) book app, selected for the BolognaRagazzi Digital Award 2016, in the digital fiction category. The analysis promotes reflection on the effect of contemporary technological transformations on literary production for children, which establish new modes of interaction in reading, raising in the reader imaginary representations that develop as the reading progresses. Therefore, the text is organized in two sections: the first presents a brief overview of the theoretical-conceptual perspectives regarding literary reading in digital media and the multiliteracies practices mobilized; the second exposes the methodological path from the theoretical support of Reception Theory (JAUSS, 1994; ISER, 1996, 1999). The analysis reveals that, although the presentation of the written texts and imagery on the same page/screen doesn't differ so much from the printed picture books, with the animation resources having the assignment of simulating the effects of the page-turning, this book app can be considered a narrative truly interactive, as it uses sound, kinetic and gamification resources as an enhancer for the understanding of the narrative plot.
\end{abstract}

KEYWORDS: Literary reading. Multiliteracies. Reception Theory. Digital Interact. 


\section{NOTAS}

${ }^{1}$ Um e-book, EBook, ebook, livro eletrônico ou livro digital "é um livro que pode ser lido em dispositivos computacionais. Normalmente contém textos e imagens, mas, não raro, recursos de multimídia e interatividade." (FLATSCHART, 2014, p. 15).

${ }^{2}$ Book app, Book-app ou picturebook-app é um aplicativo (software) que pode ser acessado em um sistema para o qual ele foi desenvolvido, permitindo utilizar as capacidades do sistema onde foi instalado (FLATSCHART, 2014).

${ }^{3}$ Os principais suportes físicos que permitem a fruição desse tipo de produção intelectual são os dispositivos móveis portáteis iPod e iPad (os quais funcionam com o sistema operacional móvel iOS da Apple Inc.) e os smartphones e tablets touchscreen (que funcionam com sistema operacional Android, desenvolvido pela Google LLC). Esses livros podem ser baixados na loja Apple Store, para os dispositivos que operam com o iOS, ou na Google Play, para os dispositivos Android.

4 Disponível em: <http://www.bookfair.bolognafiere.it/i-premi-di-bolognachildrens-book-fair/bolognaragazzi-digital-award/1034.html>. Acesso em: $18 \mathrm{fev}$. 2020.

${ }^{5}$ Disponível em: <https://www.premiojabuti.com.br>. Acesso em: 18 fev. 2020.

${ }^{6}$ A categoria Infantil Digital foi introduzida, em caráter experimental, na 57ạ edição do Prêmio (2015), mantendo-se nas edições de 2016 e 2017, sendo incorporada ao item Tecnologia da categoria Formação de Novos Leitores (eixo Inovação) a partir de 2018.

${ }^{7}$ No âmbito das aplicações digitais, o giroscópio indica qual a posição do dispositivo no espaço, se ele está girando ou permanece estático e, com essa informação, o leitor/agenciador identifica se está andando para frente ou para traz, se está parado ou em movimento, como o comportamento de uma bússola. Já o recurso do acelerômetro ajusta a visualização da tela em relação a sua posição, fazendo com que a imagem mude sua orientação na tela, caso o dispositivo seja girado (BAMAM, 2017).

${ }^{8}$ Corrêa (2010, p. 247) explica que o reconto "diz respeito à apropriação de um conto tradicional em forma de paródia, paráfrase ou outra atualização intertextual ou interdiscursiva."

\section{REFERÊNCIAS}

BAMAM, Charles. Design de livros didáticos digitais: considerações centradas no usuário. Natal: Editora IFRN, 2017. 
CORRÊA, Hércules Tolêdo. Contos, recontos e reendereçamentos: uma mesma matriz, diferentes retextualizações para públicos e gestos diversos. In: AGUIAR, Vera Teixeira de; CECCANTINI, João Luís (Org.). Teclas e dígitos: leitura, literatura e mercado. São Paulo: Cultura Acadêmica, 2010, p. 243-257.

CORRERO, Cristina; REAL, Neus. Panorámica de la literatura digital para la educación infantil. Textura, Canoas, n. 32, p. 224-244, set./dez. 2014.

CORSO, Diana Lichtenstein; CORSO, Mário. Fadas no divã: psicanálise nas histórias infantis. Porto Alegre: Artmed, 2006.

COSCARELLI, Carla Viana. Navegar e ler na rota do aprender. In: COSCARELLI, Carla Viana (Org.). Tecnologias para aprender. 1. ed. São Paulo: Parábola Editorial, 2016. p. 61-80.

COSSON, Rildo. Círculos de leitura e letramento literário. São Paulo: Contexto, 2014.

ECO, Umberto. Sobre literatura. 2. ed. Rio de Janeiro: Record, 2003.

FERREIRA, Eliane Aparecida Galvão Ribeiro. Construindo histórias de leitura: a leitura dialógica enquanto elemento de articulação no interior de uma "biblioteca vivida". 2009. 456 f. Tese (Doutorado em Letras) - Faculdade de Ciências e Letras, Universidade Estadual Paulista "Júlio de Mesquita Filho", Assis, 2009.

FLATSCHART, Fábio. Livro digital etc. Rio de Janeiro: Brasport, 2014.

FREDERICO, Aline. O futuro do leitor ou o leitor do futuro: o livro infantil interativo e os letramentos múltiplos. Cadernos de Letras da UFF, Niterói, v. 26, n. 52, p. 101120, jan./jun. 2016.

GOSCIOLA, Vicente. Roteiro para as novas mídias: do cinema às mídias interativas. 2. ed., rev. e ampl. São Paulo: SENAC São Paulo, 2008.

HAYLES, N. Katherine. Literatura eletrônica: novos horizontes para o literário. São Paulo: Global; Passo Fundo: UPF Editora, 2009.

ISER, Wolfgang. A interação do texto com o leitor. In: JAUSS, Hans Robert et al. A literatura e o leitor: textos de estética da recepção. Tradução de Luiz Costa Lima. Rio de Janeiro: Paz e Terra, 1979. p. 83-132. 
ISER, Wolfgang. $\mathbf{O}$ ato da leitura: uma teoria do efeito estético. Tradução de Johannes Kretschmer. São Paulo: Ed. 34, 1996. v. 1.

ISER, Wolfgang. 0 ato da leitura: uma teoria do efeito estético. Tradução de Johannes Kretschmer. São Paulo: Ed. 34, 1999. v. 2.

JAUSS, Hans Robert. A história da literatura como provocação à teoria literária. Tradução de Sérgio Tellaroli. São Paulo: Ática, 1994.

JOUVE, Vincent. A leitura. São Paulo: Editora UNESP, 2002.

KAPP, Karl M. The gamification of learning and instruction: game-based methods and strategies for training and education. San Francisco: Pfeiffer, 2012.

KIRCHOF, Edgar Roberto. Como ler os textos literários na era da cultura digital? Estudos de Literatura Brasileira Contemporânea, Brasília, n. 47, p. 203-228, jan./jun. 2016.

KLEIMAN, Angela B. Texto \& leitor: aspectos cognitivos da leitura. 14. ed. Campinas: Pontes, 2011.

KRESS, Gunther R.; VAN LEEUWEN, Theo. Reading images: the grammar of visual design. New York: Routledge, 1996.

LAJOLO, Marisa; ZILBERMAN, Regina. Literatura infantil brasileira: uma nova/outra história. Curitiba: PUCPRess, 2017.

LEFFA, Vilson J.; MARZARI, Gabriela Q. Design da página interativa na perspectiva da semiótica social. Linguagem em (Dis)curso, Tubarão, v. 12, n. 2, p. 495-516, maio/ago. 2012.

LINDEN, Sophie Van der. Para ler o livro ilustrado. São Paulo: Cosac Naify, 2011.

MACHADO, Paulo Henrique; REMENCHE, Maria de Lourdes Rossi. Leitura e produção do livro de literatura infantil: do analógico ao digital. Travessias, Cascavel, v. 11, n. 3, p. 158-177, set./dez. 2017.

MENEGAZZI, Douglas Luiz. O design de interfaces de livros infantis apps: uma revisão das características e recomendações. Textura, Canoas, v. 20, n. 43, p.215238, maio/ago. 2018. 
MENEGAZZI, Douglas Luiz; DEBUS, Eliane Santana Dias. O Design da Literatura Infantil: uma investigação do livro ilustrado contemporâneo. Calidoscópio, São Leopoldo, v. 16, n. 2, p. 273-285, maio/ago. 2018.

MOITA LOPES, Luiz Paulo da. Oficina de linguística aplicada: a natureza social e educacional dos processos de ensino/aprendizagem de línguas. Campinas: Mercado de Letras, 1996.

NOSY CROW. Goldilocks and Little Bear. Ilustrações de Ed Bryan. Londres: Nosy Crow, 2015. Book app.

NOVAIS, Ana Elisa. Compreendendo a sintaxe das interfaces. In: COSCARELLI, Carla Viana (Org.). Hipertextos na teoria e na prática. Belo Horizonte: Autêntica, 2012. p. 11-36.

PEREIRA, Thales Estefani. Storytelling em e-picturebooks e implicações cognitivas. 2017. 129 f. Dissertação (Mestrado em Artes, Cultura e Linguagens) Universidade Federal de Juiz de Fora, Juiz de Fora, 2017.

RESENDE, Beatriz. Contemporâneos: expressões da literatura brasileira no século XXI. Rio de Janeiro: Casa da Palavra, 2008.

RIBEIRO, Ana Elisa. Ler na tela: letramento e novos suportes de leitura e escrita. In: COSCARELLI, Carla Viana; RIBEIRO, Ana Elisa (Org.). Letramento digital: aspectos sociais e possibilidades pedagógicas. 3. ed. Belo Horizonte: Autêntica, 2011. p. 125150.

ROGERS, Yvonne; SHARP, Helen; PREECE, Jennifer. Design de interação: além da interação humano-computador. 3. ed. Porto Alegre: Bookman, 2013.

ROJO, Roxane. Gêneros discursivos do Círculo de Bakhtin e multiletramentos. In: ROJO, Roxane. (Org.). Escol@ conectada: os multiletramentos e as TICs. 1. ed. São Paulo: Parábola, 2013. p. 13-36.

ROJO, Roxane; BARBOSA, Jacqueline P. Hipermodernidade, multiletramentos e gêneros discursivos. São Paulo: Parábola Editorial, 2015.

SERAFINI, Frank; KACHORSKY, Danielle; AGUILERA, Earl. Picture books in the digital age. The Reading Teacher, v. 69, n. 5, p. 509-512, mar./abr. 2016. 
STICHNOTHE, Hadassah. Engineering stories? A narratological approach to children's book apps. Nordic Journal of ChildLit Aesthetics, [S.n.], v. 5, n. 1, p. 1-9, 21 jan. 2014.

TEIXEIRA, Deglaucy Jorge; GONÇALVES, Berenice Santos. A importância do design de narrativa para a literatura infantil contemporânea em formato digital. In: CONGRESSO BRASILEIRO DE PESQUISA E DESENVOLVIMENTO EM DESIGN, 12. 2016, Belo Horizonte. Anais... Belo Horizonte: Blücher Design Proceedings, 2016. p. 3955-3967.

TURRIÓN, Celia. Narrativa infantil y juvenil digital: ¿Qué ofrecen las nuevas formas al lector literario? 2014. 550 f. Tese (Doutorado em Didática da Língua e da Literatura) - Faculdade de Ciências da Educação, Universidade Autônoma de Barcelona, Barcelona, 2014.

YOKOTA, Junko; TEALE, William H. Picture books and the digital world: educators making informed choices. The Reading Teacher, v. 67, n. 8, p. 577-585, 2014.

ZUMTHOR, Paul. Performance, recepção, leitura. São Paulo: Ubu Editora, 2018.

Recebido: 09 fev. 2020

Aprovado: 12 mar. 2020

DOI: $10.3895 / \mathrm{rl} . v 22 \mathrm{n} 36.12541$

Como citar: MACHADO, Paulo Henrique; REMENCHE, Maria de Lourdes Rossi; FERREIRA, Eliane Aparecida Galvão Ribeiro. Leitura de book app de literatura infantil na perspectiva dos multiletramentos. $R$. Letras, Curitiba, v. 22, n. 36 p. 01-20, mar. 2020. Disponível em: <https://periodicos.utfpr.edu.br/rl>. Acesso em: $X X X$.

Direito autoral: Este artigo está licenciado sob os termos da Licença Creative Commons-Atribuição 4.0 Internacional.

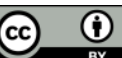

